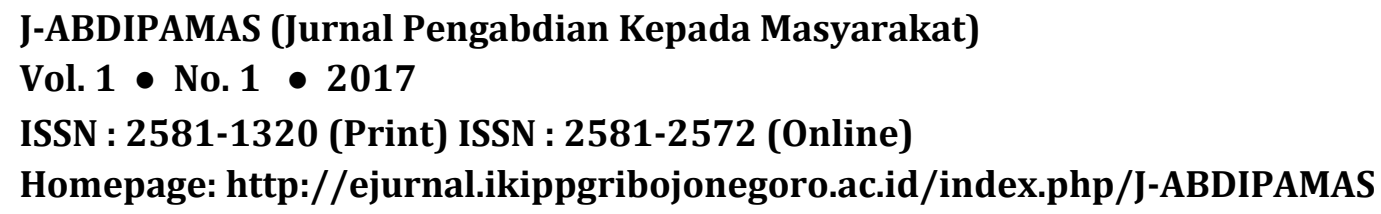

ISSN : 2581-1320 (Print) ISSN : 2581-2572 (Online)

Homepage: http://ejurnal.ikippgribojonegoro.ac.id/index.php/J-ABDIPAMAS

\title{
MENGUBAH KAWAT LISTRIK MENJADI AKSESORIS CANTIK
}

\author{
Chusna Apriyanti ${ }^{1}$, Dwi Rahayu ${ }^{2}$, Indah Puspitasari ${ }^{3}$, Ridha Kurniasih ${ }^{4}$ \\ ${ }^{1}$ STKIP PGRI Pacitan. Email: chusna.apriyanti@gmail.com \\ ${ }^{2}$ STKIP PGRI Pacitan. Email: rahayudwi949@yahoo.com \\ ${ }^{3}$ STKIP PGRI Pacitan. Email: iin_pspt@yahoo.com \\ ${ }^{4}$ STKIP PGRI Pacitan. Email: ridhkurnia@gmail.com
}

\begin{abstract}
This entrepreneurship training was aimed to make accessories from electric wire for STKIP PGRI Pacitan students. The basic idea of conducting this activity was changing the priceless electric wire into a beautiful and valuable jewelry. This activity was held on March 10-14, 2017 at campus STKIP PGRI Pacitan. Thirty eight students followed this activity from various departments. This activity was equivalent to 32 hours. Activities are divided into 4 sessions: 3 sessions for theory and practice, and 1 session equivalent to 18 hours for individual assignment. The theories include the introduction of tools and materials used, tips and tricks in starting a business, looking for good raw materials, as well as effective marketing. While the practice included activities to make various accessories made from electrical wire. Assignment involved new creations from the material that has been prepared and the participants were free to combine it with other materials. The participants were equipped with three basic techniques of electric wire: coiling, weaving/woven and netting. In the last session, the participants were given the evaluation of sustainability and monitoring of trainees. In addition, the best three works receive prizes in the form of pliers/equipment and raw materials to encourage participants to develop techniques that have been obtained in the future.
\end{abstract}

Keyword: entrepreneurship, electric wire, accessories, jewelry

\begin{abstract}
ABSTRAK
Kegiatan ini berupa pelatihan kewirausahaan membuat aksesoris dari kawat listrik bagi mahasiswa STKIP PGRI Pacitan. Ide utama dalam kegiatan ini adalah mengubah barang yang tidak terlalu bernilai seperti kawat listrik, menjadi perhiasan cantik yang bernilai jual tinggi apabila. Kegiatan ini dilaksanakan pada tanggal 10-14 Maret 2017 di kampus STKIP PGRI Pacitan. kegiatan ini diikuti oleh 38 mahasiswa dari berbagai jurusan. Kegiatan ini setara dengan 32 jam. Kegiatan dibagi menjadi 4 sesi, yaitu 3 sesi teori dan praktek selama 18 jam serta 1 sesi untuk penugasan individu selama 14 jam. Sesi teori meliputi pengenalan alat dan bahan yang digunakan, tips dan trik dalam memulai usaha, mencari bahan baku yang baik, serta pemasaran yang efektif. Sedangkan kegiatan praktik meliputi kegiatan membuat berbagai aksesoris yang berbahan dasar kawat listrik. Penugasan meliputi penciptaan kreasi baru dari materi pokok yang sudah disedikan dan para peserta bebas mengkombinasikannya dengan bahan lain. Peserta pelatihan dibekali 3 teknik dasar menganyam kawat listrik, yaitu coiling, weaving/woven dan netting. Selesai kegiatan, diberikan evaluasi keberlanjutan dan pemantauan terhadap peserta pelatihan. Selain itu, karya 3 terbaik mendapatkan hadiah berupa tang/peralatan dan bahan mentah untuk memacu peserta untuk mengembangkan teknik yang telah didapat di kemudian hari.
\end{abstract}

Kata Kunci: kewirausahaan, kawat listrik, aksesoris, perhiasan

\section{PENDAHULUAN}

Tidak ada negara yang dianggap maju bila tidak memiliki daya ekonomi yang kuat. Dan hal ini tentunya sangat erat kaitannya dengan spriti kewirausahaan dari warganya. Kewirausahaan merupakan hal yang sangat sering dibicarakan di era MEA 
seperti sekarang ini. Hal ini karena dianggap bahwa menjadi wirausaha adalah pilihan yang tepat untuk menciptakan ekonomi yang kuat baik secara individu, lingkungan, maupun untuk bangsa dan negara. Para wirausaha bisa menguatkan sektor ekonomi mikro yang nantinya akan menyerap lapangan pekerjaan bagi sekitarnya dan juga mampu menumbuhkan ekonomi masyarakat. Hal ini bisa mengurangi 'demand' terhadap lapangan pekerjaan yang semakin menyempit.

Menurut McClelland dikutip dalam artikel Elvi Rahmi (2015), salah satu faktor yang menyebabkan sebuah negara menjadi maju adalah ketika jumlah wirausahawan di negara tersebut berjumlah $2 \%$ dari populasi penduduknya. Saat ini, jumlah pelaku wirausaha di Indonesia mencapai 400 ribu jiwa atau berjumlah kurang dari 1\% populasi penduduk Indonesia. Kondisi ini sangat berbanding terbalik dengan yang terjadi di Amerika Serikat yang memiliki jumlah wirausaha sebesar $11,5 \%$ dari populasi penduduknya atau negara tetangga yaitu Singapura dengan 7,2\% warganya bekerja sebagari wirausaha. Sehingga tidak mengherankan bila kedua negara tersebut sangat maju dan mandiri dari segi ekonomi. Rukka (2011) menjelaskan bila melihat jumlah kebutuhan wirausaha baru untuk memposisikan Indonesia sebagai negara maju, setidaknya masih butuh waktu 25 tahun lagi untuk mencapainya.

Hat tersebut harus disertai dengan melakukan langkah konkrit dengan cara menambah jumlah wirausaha baru. Salah satu caranya adalah dengan menciptakan wirausahara baru dari lulusan perguruan tinggi, meskipun ada beberapa kendala yang mungkin muncul. Salah satunya adalah mindset mereka yang masih memilih untuk melamar pekerjaan yang menawarkan kemudahan dan kenyamanan serta keamanan. Ini terbukti dengan semakin meningkatnya jumlah pendaftar pegawai negeri sipil (PNS) dari tahun ke tahun. Sehingga, apabila dari mereka tidak mendapatkan pekerjaan, akan muncul masalah baru yaitu pengangguran. Bahkan muncul istilah "pengangguran terdidik", yaitu mereka para sarjana yang belum bekerja. Masalah lainnya adalah kurangnya kompetensi mereka dalam berwirausaha.

Menurut Nickels, "Entrepreneurship is accepting the risk of starting and running business", yang berarti Kewirausahaan adalah menerima resiko dari memulai dan menjalankan bisnis (2002:166). Ditambahkan oleh Soeparman Spemahamidjaja (1980), kewirausahaan adalah suatu kemampuan (ability) dalam berfikir kreatif dan berperilaku inovatif yang dijadikan dasar, sumber daya, tenaga penggerak tujuan, siasat kiat dan proses dalam menghadapi tantangan hidup. Menurut Keputusan Menteri Koperasi dan Pembinaan Pengusaha Kecil Nomor 961/KEP/M/XI/1995, kewirausahaan adalah semangat, sikap, perilaku, dan kemampuan seseorang dalam menangani usaha atau kegiatan yang mengarah pada upaya mencari, menciptakan, serta menerapkan cara kerja, teknologi dan produk baru dengan meningkatkan efisiensi dalam rangka memberikan pelayanan yang lebih baik dan atau memperoleh keuntungan yang lebih besar.

Menurut beberapa definisi diatas, sangat jelas bahwa untuk memulai usaha, tidak hanya tentang fasilitas, teknologi dan modal serta minat saja yang berperan. Akan tetapi juga sangat erat kaitannya dengan sikap dan karakter pelaku wirausaha itu sendiri. Berwirausaha tidak semudah menghabiskan modal untuk membangun usaha baru, 
namun lebih pada mendayagunakan semua potensi yang ada baik pada diri dan fasilitas untuk mengembangkan usaha yang terbentuk tersebut ke arah yang lebih baik. Sehingga usaha yang terbentuk tidak hanya sekilas lalu, namun akan bertahan dan terus berkembang menjadi maju.

Melihat gambaran diatas, sangat penting untuk membangkitkan jiwa berwirausaha sejak dalam bangku kuliah. Para mahasiswa harus menjadi lulusan yang berdaya saing tinggi yang tidak hanya mengandalkan menjadi job seeker tapi juga sebagai job creator. Bahkan sangat dimungkinkan mereka akan mampu menciptakan usaha baru sejak mereka masih mengenyam bangku kuliah. Lulusan berdaya saing tersebut akan ditandai dengan sejumlah kemampuan yang tinggi, baik hard skill dan softskill serta pengetahuan dibidang spiritual, emosional, maupun kreativitas dan inovasi. Hal ini harus ditunjang dengan mengintegrasikan aspek afektif, psikomotorik, dan kognitif oleh kampus tempat mereka belajar.

Salah satu langkah konkrit untuk mengawali gerakan mahasiswa berwirausaha adalah diselenggarakannya pelatihan kewirausahaan untuk mahasiswa. Pelatihan ini bertujuan untuk membekali mahasiswa tentang ide usaha yang bisa muncul dari kondisi lingkungan sekitar. Dalam pelatihan ini, mahasiswa dibekali ketrampilan untuk mengubah kawat listrik menjadi aksesoris cantik. Kawat listrik adalah barang murah yang sangat mudah dijumpai di toko alat listrik. Dengan berbagai macam teknik, lilitan kawat tersebut akan bisa diubah menjadi aksesoris cantik yang bernilai jual tinggi seperti gelang, cincin, kalung, bros, ataupun tuspin.

Tidak hanya kegiatan praktek saja, akan tetapi mahasiswa juga dibekali pembahasan tentang teori kewirausahaan, yang diantaranya meliputi cara pemasaran yang efektif, cara pengemasan yang menarik, cara penyimpanan barang agar awet, cara memilih bahan baku yang baik, dan cara menentukan harga. Sehingga mahasiswa akan mempunyai ide untuk memulai sebuah usaha dan kelak bisa mengembangkannya.

Peserta merupakan mahasiswa aktif STKIP PGRI Pacitan dari berbagai semester dan berbagai program studi. Mereka juga mempunyai latar belakang keluarga dan kondisi ekonomi yang beragam. Peserta ikut kegiatan pelatihan ini dengan cara mendaftar setelah publikasi pengumuman, dengan cara mengirim SMS ke panitia dan konfirmasi ulang sehari sebelum penyelenggaraan pelatihan.

Dari observasi dan wawancara sekilas, para peserta belum memiliki usaha sendiri dan mereka memiliki minat yang tinggi untuk berwirausaha. Ada beberapa peserta yang sudah bekerja part-time diluar waktu kuliah di tempat fotokopi maupun laundry. Seluruh peserta bertempat tinggal dan berasal dari Kabupaten Pacitan yang tersebar di berbagai Kecamatan dan Desa. Kabupaten Pacitan itu sendiri berupakan kabupaten di jawa timur yang terletak di ujung selatan dan ujung barat wilayah propinsi Jawa Timur. Berbatasan langsung dengan Kabupaten Wonogiri Jawa Tengah, Kabupaten Ponorogo serta Kabupaten Trenggalek.

Secara geografis, kabupaten Pacitan merupakan daerah pegunungan berkapur. Mata pencaharian mayoritas masyarakat Pacitan adalah petani dan nelayan. Pegunungan kars tersebut yang selama ini terkenal sebagai penghasil batu akik dan batu alam yang berkualitas bagus. Sehingga sangat mungkin untuk dimanfaatkan dengan baik 
untuk usaha masyarakat. Tidak hanya dijual bahan dan gelondongan saja, namun sangat mungkin untuk mengkreasikannya dengan ornamen lainnya seperti kawat listrik, kristal, akrilik, dll.

\section{METODE PELAKSANAAN}

Metode yang digunakan dalam pelaksanaan program ini adalah pelatihan. Pelatihan ini dilakukan selama 32 jam dengan materi yang dibagi menjadi tiga sesi dan satu sesi untuk penugasan individu. Tiga sesi materi dan praktek selama 18 jam dan penugasan selama 14 jam. Pada sesi pertama materi, peserta dibekali teori tentang konsep dasar kewirausahaan yang meliputi pengertian kewirausahaan, ciri dan karakter wirausaha, ide usaha untuk pemula, memilih bentuk dan lokasi usaha, menghadapi pesaing dan resiko usaha. Pada sesi kedua materi, peserta dibekali teori tentang memilih bahan baku, cara menentukan harga jual, pemasaran yang efektif, dan mengelola usaha dan karyawan. Sesi ketiga, para peserta dibekali praktek teknik dasar dalam membentuk kawat listrik menjadi aksesoris cantik. Peserta dibekali 3 teknik dasar yaitu coiling, netting, dan weaving/woven. Dari ketiga teknik dasar ini, peserta bisa memodifikasinya menjadi bentuk yang sangat beragam sesuai kreativitasnya.

Pelatihan ini, semua bahan disediakan oleh panitin pengabdian kepada masyarakat. Peserta diminta untuk membawa gunting potong kuku untuk alat memotong kawat agar ujungnya tidak lancip dan tidak tajam. Semua peralatan (berbagai bentuk tang) dipinjamkan selama kegiatan berlangsung. Bahan utama kegiatan ini adalah kawat listrik ukuran $1 \mathrm{~mm}, 0.8 \mathrm{~mm}$, dan $0.3 \mathrm{~mm}$. Bahan penunjang yang digunakan adalah bunga clay, ornamen kristal, peniti bros, batu agate dan beads.

\section{HASIL DAN PEMBAHASAN}

Kegiatan ini dilaksanakan pada tanggal 10-14 Maret 2017 dengan susunan kegiatan sebagai berikut:

\begin{tabular}{|c|c|c|c|}
\hline Sesi & Waktu & Kegiatan & Pelaksana \\
\hline \multirow[t]{7}{*}{ Sesi 1} & $07.00-07.10$ & Presensi peserta & Petugas \\
\hline & $07.10-07.30$ & Pembukaan dan perkenalan & Petugas \\
\hline & $07.30-09.30$ & Konsep dasar kewirausahaan & Indah Puspitasari \\
\hline & $09.30-09.45$ & Istirahat & \\
\hline & 09.45-11.30 & Memilih bentuk dan lokasi usaha & Dwi Rahayu \\
\hline & $11.30-12.30$ & Menghadapi pesaing dan resiko usaha & Ridha K. \\
\hline & $12.30-13.00$ & Tanya jawab & Petugas \\
\hline \multirow[t]{7}{*}{ Sesi 2} & $07.00-07.10$ & Presensi peserta & Petugas \\
\hline & $07.10-08.30$ & Memilih bahan baku yang baik & Chusna Apriyanti \\
\hline & $08.30-09.30$ & Menentukan harga jual & Dwi Rahayu \\
\hline & 09.30-09.45 & Istirahat & \\
\hline & $09.45-11.30$ & Pemasaran yang efektif & Indah Puspitasari \\
\hline & $11.30-12.30$ & Mengelola usaha dan karyawan & Ridha Kurniasih \\
\hline & $12.30-13.00$ & Tanya jawab & \\
\hline \multirow[t]{4}{*}{ Sesi 3} & $07.00-07.10$ & Presensi peserta & Petugas \\
\hline & $07.10-09.30$ & $\begin{array}{l}\text { Praktek teknik dasar wire jewelry (Coiling, } \\
\text { Netting, Woven/Weaving) }\end{array}$ & Chusna Apriyanti \\
\hline & 09.30-09.45 & Istirahat & \\
\hline & $09.45-13.00$ & $\begin{array}{l}\text { Lanjutan praktek teknik dasar wire jewelry } \\
\text { (Coiling, Netting, Woven/Weaving) }\end{array}$ & Chusna Apriyanti \\
\hline
\end{tabular}


Sesi 4

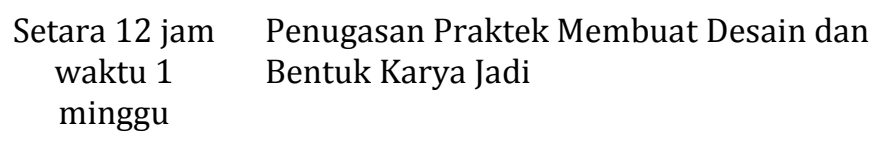

Materi inti yang disampaikan sesuai susunan seperti dibawah ini:

\section{Sesi 1}

Kegiatan awal berisi pembukaan dan perkenalan. Pada sesi pertama materi, peserta dibekali teori tentang konsep dasar kewirausahaan yang meliputi pengertian kewirausahaan, ciri dan karakter wirausaha, ide usaha untuk pemula, memilih bentuk dan lokasi usaha, menghadapi pesaing dan resiko usaha.

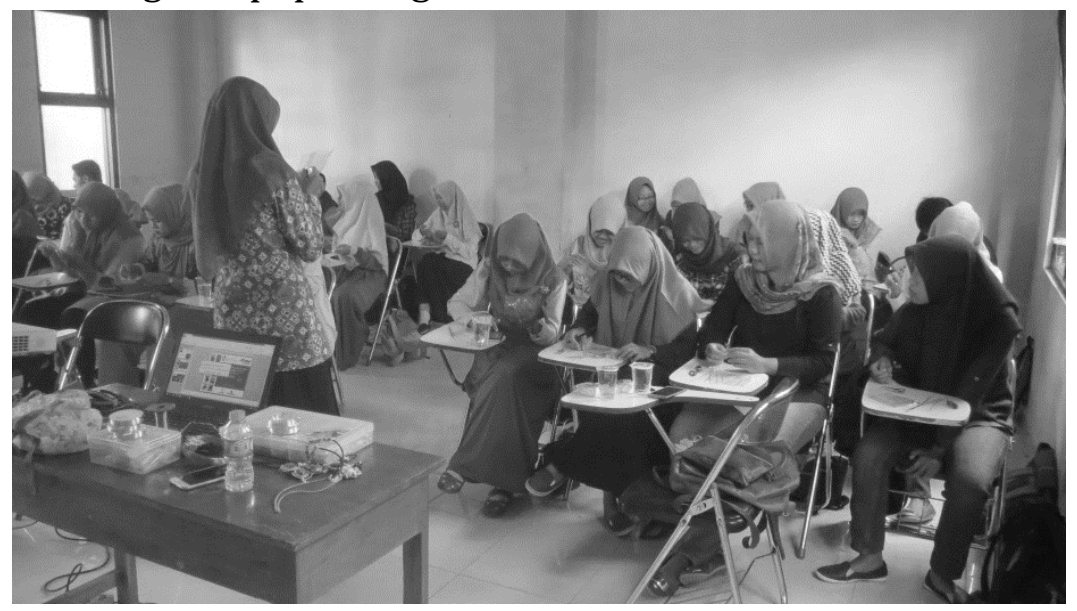

Gambar 1: Tutor Menjelaskan tentang Konsep Dasar Kewirausahaan.

\section{Sesi 2}

Pada sesi kedua materi, peserta dibekali teori tentang memilih bahan baku, cara menentukan harga jual, pemasaran yang efektif, dan mengelola usaha dan karyawan.

\section{Sesi 3}

Sesi ketiga, para peserta dibekali praktek teknik dasar dalam membentuk kawat listrik menjadi aksesoris cantik. Peserta dibekali 3 teknik dasar yaitu coiling, netting, dan weaving/woven. Dari ketiga teknik dasar ini, peserta bisa memodifikasinya menjadi bentuk yang sangat beragam sesuai kreativitasnya.

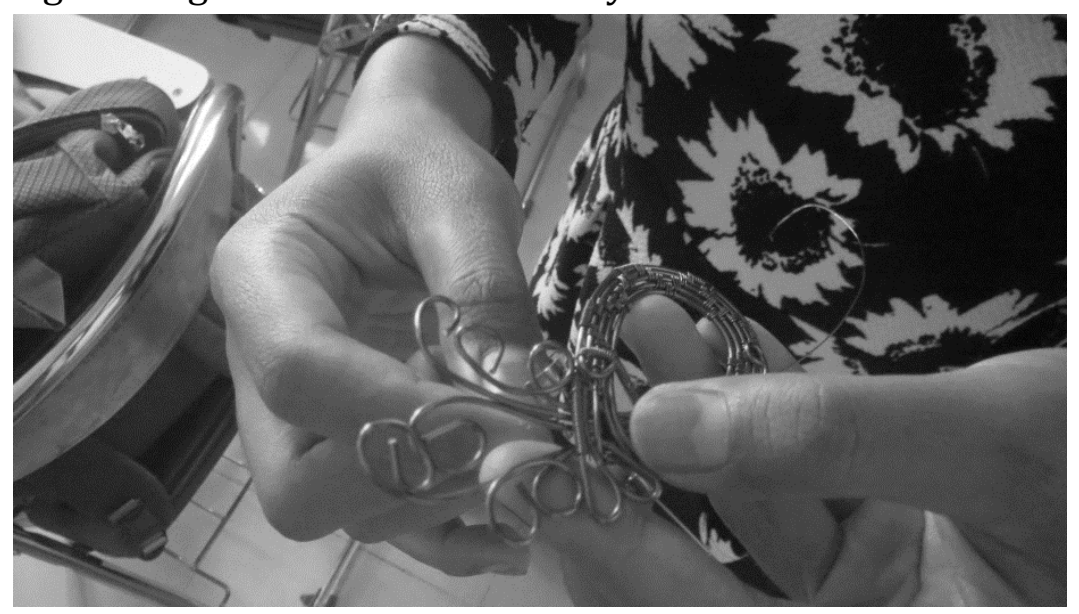

Gambar 2: Peserta Praktek Teknik Coiling 


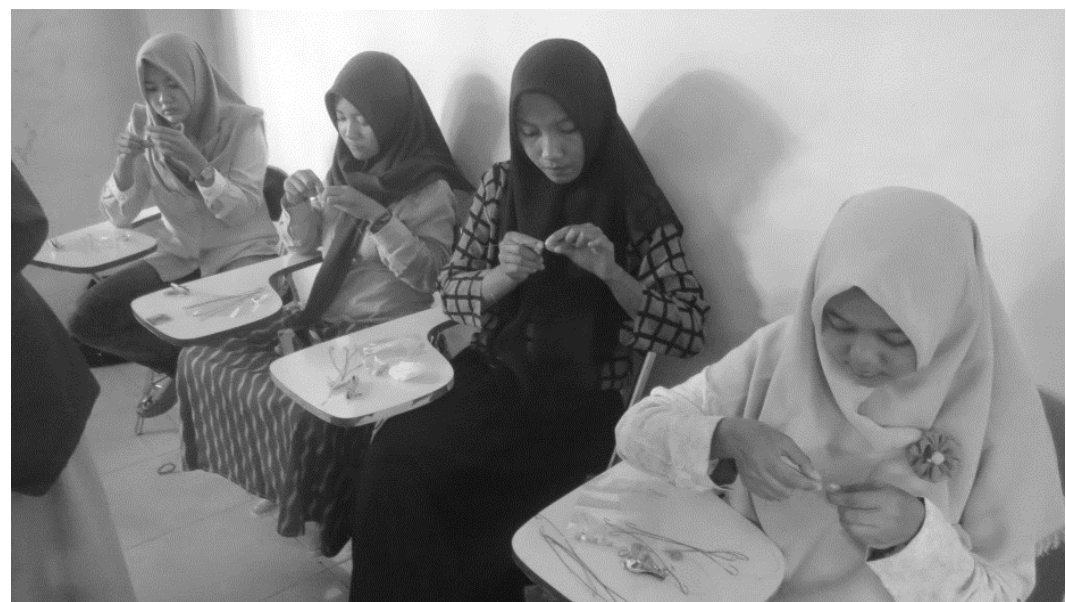

Gambar 3: Peserta Praktek Teknik Dasar Wire

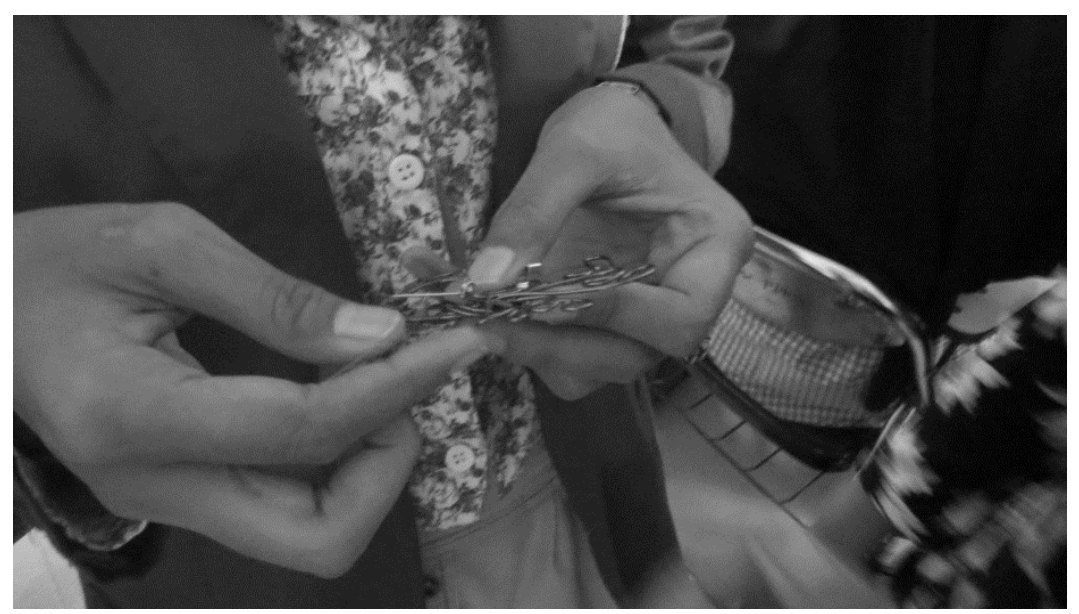

Gambar 4: Peserta Memasang Peniti Bros

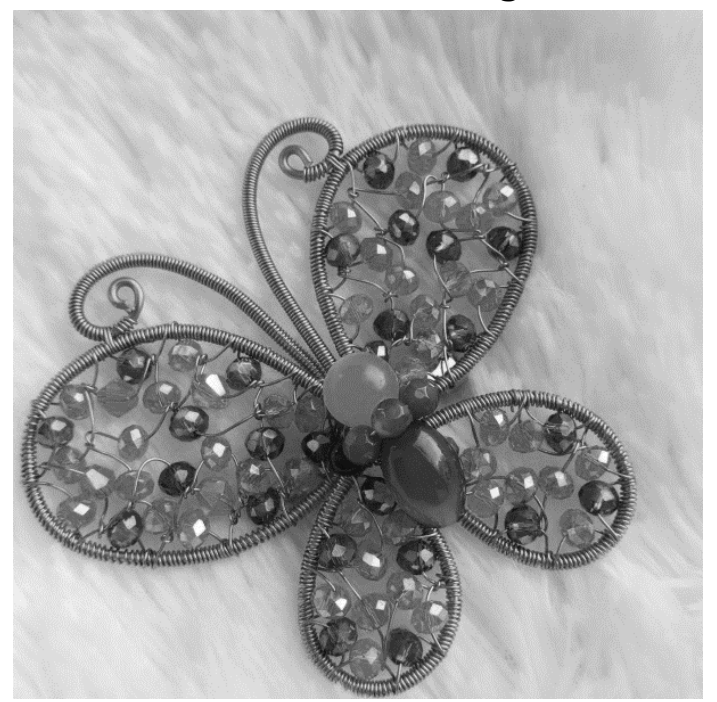

Gambar 5: Contoh Hasil Jadi Perpaduan Kawat Listrik Teknik Netting Modifikasi, Kristal Alam, dan Beads 


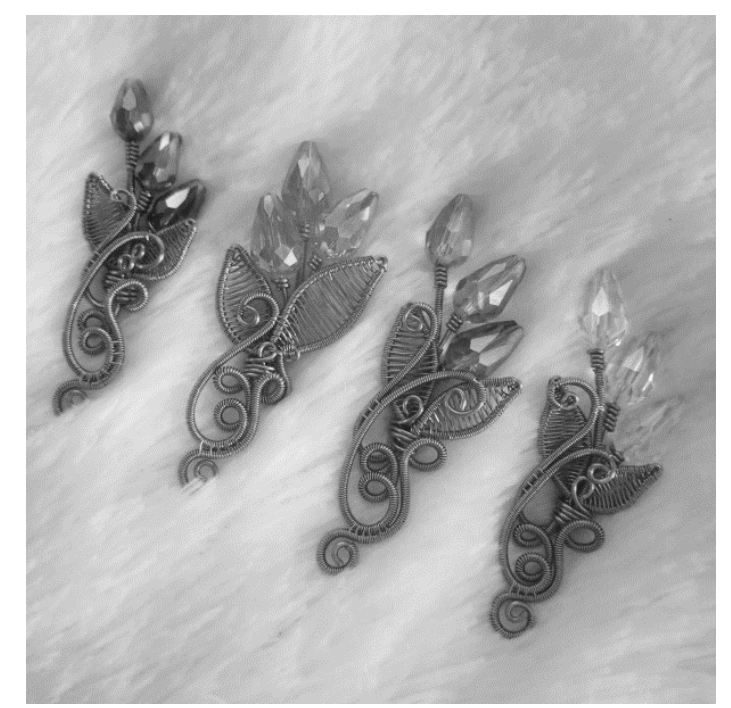

Gambar 6: Contoh Hasil Jadi Bros Ornamen Kristal Dengan Teknik Weaving dan Woven

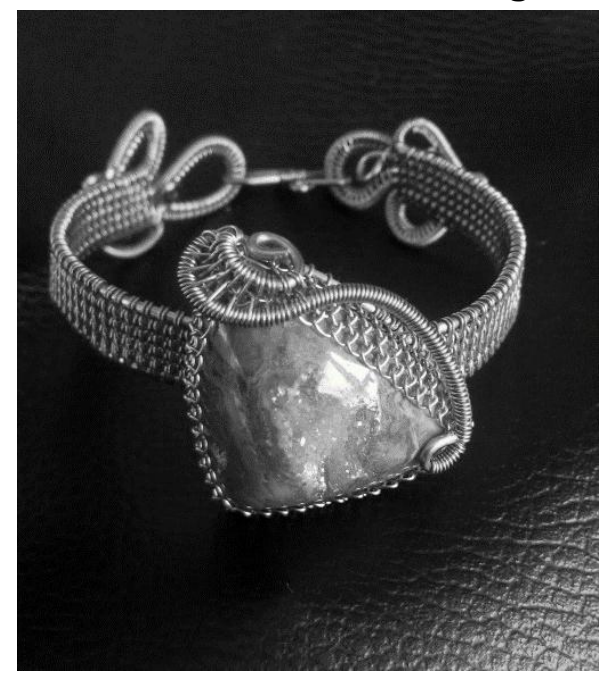

Gambar 7: Gelang Kombinasi Batu Druzy dengan Teknik Woven

Kegiatan penutup untuk rangkaian sesi pelatihan ini adalah pengumpulan hasil karya selama sesi penugasan. Sebelum sesi penugasan, peserta dibagikan bahan untuk diselesaikan di rumah sesuai dengan teknik yang telah dipelajari. Peserta diperbolehkan memadukannya dengan material lain misalnya batu, kayu, ataupun kain sebagai ornamen. Pengumpulan juga disertai judul dan nama karya serta harga jual untuk barang tersebut. Peserta juga harus membuat deskripsi tentang produknya untuk memudahkan pemasaran.

Pelatihan dapat dilaksanakan dengan baik dengan mengedepankan keterlibatan peserta. Peserta dibekali dengan teori yang cukup untuk memulai usaha serta praktik membuat perhiasan aksesoris cantik dengan bahan dasar utawa kawat listrik. Beberapa kendala yang muncul diantaranya adalah: kurang telatennya beberapa peserta dalam menganyam kawat dan kurangnya penyedia bahan penunjang yang ada di pacitan sehingga harus membeli bahan penunjang via online.

Kegiatan ini memiliki aspek keberlanjutan yang baik. Beberapa peserta intensif untuk melakukan diskusi di luar jam pelatihan dengan tutor. Salah satu dari mereka bahkan sudah mempunyai brand sendiri yang bergerak di perhiasan handmade dari kawat listrik atau disebut wire jewelry. 


\section{SIMPULAN}

Pelatihan ini dilakukan selama 32 jam dengan materi yang dibagi menjadi tiga sesi dan satu sesi untuk penugasan individu. Tiga sesi materi dan praktek selama 18 jam dan penugasan selama 14 jam. Pada sesi pertama materi, peserta dibekali teori tentang konsep dasar kewirausahaan Pada sesi kedua materi, peserta dibekali teori tentang memilih bahan baku, cara menentukan harga jual, pemasaran yang efektif, dan mengelola usaha dan karyawan. Sesi ketiga, para peserta dibekali praktek teknik dasar (coiling, netting dan woven/weaving) dalam membentuk kawat listrik menjadi aksesoris cantik. Sesi terakhir meliputi penugasan.

\section{DAFTAR RUJUKAN}

Elvi Rahmi. (2015). Re-Design Mata Kuliah Kewirausahaan Sebagai Upaya Melahirkan Entrepreneur Muda. Fakultas Ekonomi Universitas Negeri Padang.

Keputusan Menteri Koperasi dan Pembinaan Pengusaha Kecil Nomor 961/KEP/M/XI/1995.

Nicklels, William G. (2002). Understanding Business. Mc Graw Hill Book Company. New York.

Rukka, Muhammad Rusli. (2011). Buku Ajar Kewirusahaan-Makassar. Lembaga Kajian dan Pengembangan Pendidikan Universitas Hasanuddin.

Soeparman Soemahamidjaja.(1980). Membina Sikap Mental Wirausaha. Jakarta : Gunung Jati. 